\title{
Possibilidades das fontes orais: um exemplo de pesquisa ${ }^{1}$
}

Verena Alberti e Amilcar Araujo Pereira*

Resumo: 0 artigo tem como objetivo apresentar reflexões sobreas possibilidades de utilizaçãa de fontes orais em pesquisas históricas. Para tanto, tomamos como exemplo nossa pesquisa, intitulada "H istória do movimento negro no Brasil: constituição de acervo de entrevistas de história oral" , desenvolvida entre 2003 e 2007, no Centro de Pesquisa e D ocumentação da H istória Contemporânea do Brasil (CPD OC) da Fundação G etulio Vargas. São discutidos, entre outros temas, as articulações entre história oral ehistória política, o cruzamento entrefontes orais e fontes escritas e as possibilidades de ampliação do conhecimento sobre o passado proporcionadas pela história oral.

Palavras-chave: H istória oral. M ovimento negro. Brasil contemporâneo

\footnotetext{
* VerenaAlberti (verena.alberti@ fgv.br), pesquisadorado ProgramadeH istória O ral do Centro dePesquisaeD ocumentação deH istóriaContemporâneado Brasil (CPD OC) da Fundação G etulio Vargas e professora da E scola A lemã Corcovado, no Rio de Janeiro, éformada em históriapelaU niversidade Federal Fluminense (UFF), mestreem antropologiasocial pelo ProgramadePós-G raduação em AntropologiaSocial (PPGAS) do M useu N acional (UFRJ) e doutora em teoria da literatura pela Universidade de Siegen (A lemanha). A milcar A raujo Pereira (amilcarpereira@ hotmail.com) éformado em históriapelaUFRJ, mestrepelo ProgramadePós-G raduação em Ciências Sociais da U niversidade do Estado do Rio de Janeiro (UERJ) e doutorando em história na UFF. É bolsistado Conselho N acional deD esenvolvimento Científico eTecnológico (CN Pq), com doutorado sanduíchenaJ ohns H opkins U niversity, em Baltimore, EUA, realizado durante 0 ano de 2008.
} 
Possibilidades das fontes orais: um exemplo de pesquisa

A pauta para a mesa-redonda "O historiador e as fontes orais", preparada pelos organizadores do IX Encontro E stadual de H istória da A npuh do Rio G rande do Sul, de julho de 2008, continha algumas sugestões de questões a serem discutidas pelos palestrantes:

- 0 que documenta a fonte oral?

- A té que ponto a história oral proporciona acesso a informações empíricas? Q uais possibilidades e limites desse acesso?

- D e que forma a subjetividade pode ser útil ao historiador?

- Como cruzar as fontes orais com outros tipos de fonte?

- Q ue aspectos epistemológicos e éticos estão em jogo na crítica do testemunho oral?

N ão será possível tratar de todas as questões neste artigo, mas as manteremos como pano de fundo de nossas reflexões. Partiremos de uma pesquisa concreta, que desenvolvemos entre 2003 e 2007, no Centro de Pesquisa e D ocumentação da H istória Contemporânea do Brasil (CPD OC) da Fundação G etulio Vargas. A pesquisa, intitulada " $\mathrm{H}$ istória do movimento negro no Brasil: constituição de acervo de entrevistas de história oral", resultou na formação de um banco de 39 entrevistas de história oral, totalizando 110 horas gravadas, com militantes de diferentes regiões do Brasil do movimento negro contemporâneo - nome que tem sido dado ao conjunto demovimentos negros surgido a partir da década de $1970 .{ }^{2}$

G ostaríamos de iniciar a reflexão sobre as possibilidades das fontes orais apresentando dois documentos textuais que integram o A rquivo E rnesto G eisel do CPD O C. ${ }^{3}$ A mbos são documentos do Serviço N acional de Informações (SN I), criado em junho de 1964, cerca de dois meses depois do início da ditadura militar. 0 primeiro é a "A preciação Sumária" nำ25, referente ao período de 3 a 9 de julho de 1978. E m sua página 3, na seção dedicada à "O pinião Pública", vemos um relato, em certa medida preocupado, sobre a manifestação do "M ovimento N egro Contra a D iscriminação Racial", em julho daquele ano. Diz o relato: 
Realizou-se em São Paulo/ SP, no dia 07 jul 1978, na área fronteiriça ao Teatro M unicipal, junto ao V iaduto do Chá, uma concentração organizada pelo autodenominado 'M ovimento U nificado Contra a D iscriminação Racial', integrado por vários grupos, cujos objetivos principais anunciados são: denunciar, permanentemente, todo tipo de racismo e organizar a comunidade negra.

E mbora não seja, ainda, um 'movimento de massa', os dados disponíveis caracterizam a existência de uma campanha para estimular antagonismos raciais no País e que, paralelamente, revela tendências ideológicas de esquerda.

Convém assinalar que a presença no BRASIL de ABDIAS DO NASCIMENTO, professor em NOVA IORQUE, conhecido racista negro, ligado aos movimentos de libertação na ÁFRICA, contribuiu, por certo, para a instalação do já citado 'M ovimento U nificado'. ${ }^{4}$

A inda que estejamos diante de um documento produzido por um órgão de inteligência do regime militar, podemos aceitar como verdadeiros os objetivos do movimento então destacados: "denunciar todo tipo de racismo", de um lado, e "organizar a comunidade negra", de outro. D o mesmo modo, é verdadeira a informação de que o Movimento U nificado Contra a D iscriminação Racial - 0 chamado MUCDR, que pouco tempo depois se transformou no M ovimento N egro U nificado, o M N U - era "integrado por vários grupos".

D esde 0 início da década de 1970, é possível registrar a formação de entidades que, como diz o relatório do SN I, buscavam denunciar o racismo e organizar a comunidade negra. E m 1971, foram fundados o G rupo Palmares, em Porto A legre, e o G rupo de Teatro E volução, do interior do estado de São Paulo; em 1972, o Centro de Cultura e A rte N egra (Cecan), em São Paulo; em 1974, a Sociedade Cultural Bloco Afro Ilê Aiyê e a Sociedade de E studos da Cultura N egra no Brasil (Secneb), em Salvador, e a Sociedade de Intercâmbio Brasil-África (Sinba), no Rio de Janeiro, cujo jornal 
Sinba circulou de 1977 até 1980; em 1975, o Instituto de Pesquisas das Culturas N egras (IPCN ), no Rio de Janeiro, o G rupo de Trabalho André Rebouças (GTAR), criado na Universidade Federal Fluminense (UFF), em N iterói (RJ), o Centro de Estudos Brasil-Á frica (Ceba), em São G onçalo (RJ), o I nstituto Brasileiro de E studos A fricanistas (I bea) e a A ssociação Casa de Arte e Cultura Afro-Brasileira (A cacab), em São Paulo; e em 1976, o N úcleo Cultural Afro-Brasileiro, em Salvador.

Sobre o I bea, aliás, é interessante mencionar outra apreciação sumária do SN I, datada de novembro de 1975, também encontrada no Arquivo $\mathrm{G}$ eisel, que informa que a instituição promoveu, no dia 13 de outubro de 1975, como parte de seu "Curso de Extensão sobre o N egro no Brasil", uma conferência de Florestan Fernandes. ${ }^{5}$ Como era de se esperar, F lorestan, cassado pelo A -5, foi ali apontado como comunista e subversivo.

É possível verificar que praticamente todas as entidades se denominam "centros culturais", "institutos de pesquisa", "centros de estudo", "de intercâmbio", etc. D e um lado, essa escolha se deve ao impedimento legal de se registrar uma entidade como sendo "racial". D e outro, ao próprio tipo de atividades que desenvolviam: de leitura, estudos e manifestações culturais - o que era uma estratégia de ação importante naquele momento.

0 segundo documento que gostaríamos de apresentar foi escrito seis meses antes. É a "A preciação especial" de 2 de janeiro de 1978, classificada como dizendo respeito ao assunto "O pinião Pública", "retrospecto de 1977 e perspectivas para 1978". N a página 4, item f, encontramos uma apreciação sobre as "manifestações de racismo negro" no Rio, em São Paulo e na Bahia. 0 item se segue a outros que vinham relatando a infiltração comunista nos meios de comunicação, a atuação da imprensa alternativa, de rádios e emissoras de TV, que, entre outras coisas, vinham dando cobertura ao movimento estudantil. D iz a apreciação: 
Continuando o acompanhamento que vinha sendo feito, com mais intensidade, desde 0 ano passado, foram detectadas várias manifestações de Racismo N egro, exteriorizado de forma mais concreta no movimento "Soul", que tomou conta da juventude negra do RIO DE JANEIRO e SÃO PAULO, e começou a espalhar-se para o N ordeste com 0 movimento "BLACK BAHIA". Também os institutos de aultura afro-brasileira, ampliando-se, ultimamente, têm, em muitos casos, parcela de responsabilidade no estímulo a atitudes racistas e revanchistas, por parte de jovens negros, que vêem neles e no movimento "Black" uma maneira de auto-afirmação racial. Esses movimentos, caso continuem a crescer e se radi-calizar, poderão vir a originar conflitos raciais.

0 item g, que se segue ao citado anteriormente, também é interessante. Ele já trata de outro assunto: do "M ovimento G ay", que, para o SN I, nada mais é que a promoção do homossexualismo. 0 "M ovimento $\mathrm{G}$ ay", segundo o relatório, constituía-se em "mais uma ameaça à instituição da família e da moral, alicerces da sociedade". 0 item h dedica-se à atuação da A ssociação Brasileira de Imprensa ( $\mathrm{ABI}$ ), da O rdem dos Advogados do Brasil (OAB), do Clero Católico e do Movimento Feminino pela Anistia - que se sobressaíram, segundo o autor do retrospecto de 1977, por sua "ação contestatória".

E sses não são evidentemente os únicos documentos produzidos pelos órgãos de informação da época sobre a atividade de militantes e organizações do movimento negro. ${ }^{6} 0$ trabalho com documentos é especialmente interessante, pois, em geral, eles respondem a perguntas que nos fazemos hoje, mas as quais eles não tinham, originalmente, intenção de responder. 0 que um breve olhar sobre esses documentos pode revelar? Q ue o movimento negro contemporâneo, surgido na década de 1970, está inserido num contexto específico da história recente do Brasil - 0 da Abertura política, iniciada em 1974 - , do mesmo modo que as atuações da imprensa 
alternativa, de organizações da sociedade civil como a OAB e a $A B I$, e do "M ovimento G ay", entre outros.

0 ato público de 7 de julho de 1978, nas escadarias do Teatro M unicipal de São Paulo, acabou resultando na formação, no mesmo ano, do M ovimento $\mathrm{N}$ egro U nificado, o M N U, entidade que existe $\infty$ até hoje e que parece ter sido responsável pela difusão da noção entidades e ações a partir daquele momento.

Milton Barbosa, ${ }^{7}$ uma das principais lideranças do ato, explicou-nos na entrevista que fizemos em sua casa, em São Paulo, como se deu a articulação e a própria manifestação:

E m 1978 nós fizemos uma reunião em São Paulo, no Centro de Cultura e Arte N egra, no dia 18 de junho, e criamos um movimento. Participaram várias entidades: 0 Cecan, de que a gente fazia parte; tinha um grupo Brasil Jovem, que era um pessoal da Casa Verde; tinha lá um centro de estudos afro-brasileiros, que eram os irmãos Wilson e Celso Prudente e o Clóvis M oura; ${ }^{8}$ veio o filho do A dalberto Camargo, que era deputado federal, representando a Câmara de Comércio A fro-Brasileira; ${ }^{\circ}$ o N úcleo Socialista A fro-Latino-A mérica ${ }^{10}$ - era o N úcleo N egro Socialista, mas, no surgimento do MNU, nós não estávamos mais na Liga O perária, nem na Convergência Socialista. ${ }^{11}$

Percebe-se aqui que havia muitas entidades envolvidas, bem como que havia uma relação bastante estreita com grupos de esquerda.

M iltão, como é conhecido, prossegue contando as motivações do ato, que não aparecem no breve relato do SN I:

As pessoas já foram para a reunião para criar o movimento. A conteceu que um rapaz, primo do Rafael Pinto, o Robson Silveira da Luz, trabalhador, pai de família, foi preso em uma feira, acusado de estar roubando frutas. E le foi preso 
no $44^{\circ} \mathrm{D}$ istrito Policial de G uaianazes e foi torturado, vindo a falecer em conseqüência das torturas. I sso revoltou a população negra e saiu no jornal Folha deS. Paulo. Logo em seguida teve a discriminação de quatro garotos negros, que foram impedidos de treinar no time infantil de voleibol do Clube de Regatas Tietê.12 Também nos deixou enraivecidos. (...) Convidamos várias entidades e fizemos essa reunião no dia 18 de junho. $N$ ela discutimos a criação de um movimento unificado contra a discriminação racial e o lançamento público no dia 7 de julho.

Foi escolhido 07 de julho porque era mais ou menos 0 tempo que daria para a gente preparar a manifestação. Tínhamos umas três semanas, tempo suficiente para rodar material, fazer contato com a imprensa, com a I greja, setores de direitos humanos, contatos internacionais. Tinha uma menina que participou com a gente, uma judia, a M irna G rzich, tinha o Barrinhos, que era o namorado dela, e eles nos ajudaram a fazer contatos internacionais e com a imprensa. N esse período, nós fazíamos reuniões quase que diárias para organizar essa atividade, elaboramos a carta para distribuir - basicamente fomos eu e Hamilton que escrevemos aquela carta, em discussão com o grupo todo. N aquela discussão tinha N eusa Maria Pereira, Hamilton Cardoso, O svaldo Rafael Pinto Filho, Antônio Leite, E duardo de O liveira, o Júnior filho do A dalberto Camargo, Vanderlei José Maria, o José A dão, conhecido como A dãozinho, que era trabalhador do Correio. E ntão tinha uma quantidade grande de pessoas.

A qui aparece claramente uma das grandes possibilidades da história oral: conhecer como se dão as articulações; quem participa; como e por que decisões foram tomadas. Por exemplo, por que foi escolhido 07 de julho e que pessoas estavam envolvidas. E ssas informações prosseguem na passagem seguinte, em que Miltão relata como foi decidida e executada a estratégia de solicitar permissão ao secretário de Segurança de São Paulo, que à época era Ê nio V iegas M onteiro de Lima, e não E rasmo D ias, como ele supôs. 
Possibilidades das fontes orais: um exemplo de pesquisa

E inclusive tivemos que usar de esperteza: havia setores um pouco mais conservadores meio que querendo pular fora, porque exigiram que a gente fosse entregar uma carta para o secretário de Segurança do estado. A gente percebeu, nesse dia, que a gente tinha que manter aquele setor e tinha que entregar a carta lá para o secretário de Segurança. E elaboramos uma carta meio besta, dizendo que a gente ia fazer uma manifestação para evitar que forças alienígenas... U m tema esquisito. E foi entregue para o secretário de Segurança, que, naquele momento, eu acho que era o $\mathrm{E}$ rasmo D ias. ${ }^{13}$

A próxima passagem mostra que a articulação com a grande imprensa incluiu uma reunião com o jornalista Boris Casoy:

E u dei uma sorte que, no dia, a gente tinha uma reunião com o Boris Casoy na Folha deS. Paulo e eu fui convocado para ir a essa reunião - nós estávamos discutindo o apoio, para sair na F olha de S. Paulo. Então não tive que ir lá pagar o mico de entregar uma cartinha para o secretário de Segurança. Foi uma comitiva, acho que o E duardo de 0 liveira, o Antônio Leite, e foi bom isso porque, nesse contato, em função daquela cartinha, liberaram a praça. N ão montaram esquema de repressão. E nós distribuímos carta à população convocando.

Finalmente, o que aconteceu no dia:

No dia, nos encontramo na galeria N ova Barão e saímos meio que abraçados uns nos outros, morrendo de medo. E u mesmo tinha ido no banheiro toda hora no meu trampo - nessa época eu ainda trabalhava no M etrô. A ssim, susto mesmo. Teve gente que fal ou que foi no banheiro toda hora mesmo, um troço doido. Estávamos assustados e aí nós caminhamos: "Vamos nessa!" N os inspiramos em todo mundo, M artin Luther K ing, todo mundo e "vamos que vamos". E caminhamos para as escadarias do Teatro M unicipal. 0 Cupamos espaço, colocamos faixa lá. Tivemos presença também 
do A bdias do N ascimento, L élia G onzalez, vieram o A mauri e o Yedo do Rio, estavam aí pessoas de cidades do interior, recebemos cartas da $B$ ahia. Recebemos um documento dos presos da Casa de $D$ etenção, porque nós fazíamos um trabalho dentro da Casa de D etenção (...). Foi um ato muito bonito.

A gente percebeu, imediatamente quando ocupamos a praça, que a polícia se arrependeu de ter deixado, pelas coisas que eles falavam, ficavam xingando e ameaçando. M as aí já era tarde. Foi um negócio barra-pesada, não foi molenão. É poca de ditadura militar. A gora, nós nos articulamos muito bem com a I greja, com a imprensa toda. A mesma grande imprensa que estava contra a ditadura militar, que queria derrotar 0 regime, abriu espaço para nós. E ntão nós trabalhamos com todas essas contradições. A articulação internacional foi muito bem feita. A migos nossos que vieram da Guiné-Bissau, da Argentina, dos E stados U nidos vibraram quando viram as nossas fotos, a manifestação.

Cabe notar que as entrevistas com militantes do movimento negro mostram que é muito expressiva a circulação de referenciais que vinham dos movimentos de libertação da África - especialmente, nesse momento, a portuguesa - e do movimento pelos direitos civis nos EUA. ${ }^{14}$

E novamente, alguns detalhes da organização do evento:

Tudo foi feito com muita discussão, com muito rigor, a gente analisou cada passo. Por exemplo: o Vanderlei José M aria propôs que eu fosse o presidente do ato. A to público não tem presidente. M as como era um negócio muito barrapesada, tinha que ter um controle das ações. E ntão fui eleito para ser o presidente. D everia haver apenas um comando. $\mathrm{E}$ de fato funcionou, porque a polícia provocou muito, mas ninguém aceitou as provocações. $E$ foi um ato vitorioso que estourou no Brasil inteiro e no mundo inteiro. Q uando nós ocupamos a praça, não tinha mais como eles reprimirem porque o Brasil vendia a imagem de país não racista. Estava 
Possibilidades das fontes orais: um exemplo de pesquisa

comprando petróleo na N igéria, em Angola, e foi o primeiro país a reconhecer a libertação dos países africanos, em especial A ngola. ${ }^{15}$ E ntão eles ficaram de mãos amarradas. Q uando nós pisamos lá no Teatro M unicipal, tínhamos conquistado uma vitória importante.

O 0 utros entrevistados relataram o evento, as articulações que $\infty$ levaram ao ato e as negociações posteriores, que resultaram na formação do MNU. É muito interessante acompanhar esse passo a passo a partir da visão de cada um, o que, contudo, não será possível realizar aqui. ${ }^{16}$

M as a narrativa de M ilton Barbosa já permite observar a articulação estreita entre história oral e história política, como já tem sido observado por muitos pesquisadores. ${ }^{17}$ U ma história política entendida não como história dos "grandes homens" e dos "grandes feitos", e sim como estudo das diferentes formas de articulação de atores e grupos, trazendo à luz a importância das ações dos indivíduos e de suas estratégias.

I sso nos permite voltar à pauta da mesa-redonda "O historiador e as fontes orais", especialmente a duas das questões colocadas: "até que ponto a história oral proporciona acesso a informações empíricas?" e "como cruzar as fontes orais com outros tipos de fonte?"

A lém da relação estreita da história oral com a história política, não podemos esquecer também sua relação com a história em geral, incluindo em tais relações desde a pesquisa e a análise de documentos até as possibilidades de conhecimento do passado. $\mathrm{No}$ desenvolvimento de pesquisas com o método da história oral, recorremos a fontes primárias e secundárias para nos preparar para as entrevistas, que, por sua vez, transformam-se em fontes para novas pesquisas. Cruzar fontes orais com outros tipos de fonte é, pois, parte integrante da metodologia.

Q uanto à ampliação do conhecimento do passado, muitos já observaram como a história oral permite alterar a "hierarquia de 
significações historiográficas", no dizer da historiadora italiana Silvia Salvatici, que faz um paralelo entre a história oral e a história de mulheres, à medida que ambas possibilitam 0 acesso à pluralidade. ${ }^{18}$ Tomemos como exemplo a periodização. 0 estudo da história se enriquece muito quando conhecemos novos marcos, e essas possibilidades de perspectivação do passado aparecem com freqüência quando trabalhamos com a história oral. E $\mathrm{m}$ algumas pesquisas de história oral desenvolvidas na A lemanha e na F rança, por exemplo, chamou a atenção dos pesquisadores o fato de a cronologia relativa ao período da Segunda G uerra M undial aparecer diferenciada nas entrevistas. $\mathrm{N}$ a A lemanha, muitos operários entrevistados em um estudo sobre as condições de vida do vale do Ruhr não se lembravam do ano da ascensão de $\mathrm{H}$ itler ao poder, 1933, mas se lembravam claramente dos anos de 1934, 1935 e 1936, nos quais se encerrou o desemprego em massa em virtude do crescimento da indústria bélica. ${ }^{19}$ I sso não significa, porém, que devemos esquecer os marcos nacionais em prol da periodização que sobressai das entrevistas; ao contrário, é impossível saber o que 0 ano de 1935 significa para os entrevistados sem considerar o ano de 1933, na história da Alemanha.

No caso da pesquisa sobre o movimento negro, pudemos detectar alguns marcos importantes, que sobressaem de nossas entrevistas. 0 ano de 1978 é, sem dúvida, um deles - aliás, ele também é conhecido no movimento sindical como 0 ano do surgimento do chamado "novo sindicalismo". A repercussão nacional do ato nas escadarias do Teatro M unicipal de São Paulo, que resultou na criação do M N U, possibilitou a criação de muitas organizações em diferentes estados do país, e isso aparece nitidamente nas entrevistas. Logo no ano seguinte, em 1979, formaram-se o Centro de Cultura N egra (CCN) do Maranhão; a Associação Cultural Zumbi (ACZ), em M aceió; os blocos afro O lodum e M alê D ebalê, em Salvador; 0 Grupo N egro da Pontifícia Universidade Católica (PUC) de São Paulo, e o G rupo de U nião e Consciência N egra (G rucon), inicial- 
mente vinculado à I greja Católica. E m 1980, foi a vez do Centro de E studos e D efesa do N egro do Pará (Cedenpa). H ouve ainda entidades formadas no Espírito Santo, no Rio de Janeiro e em M inas G erais.

0 marco seguinte foi 0 ano de 1988, por duas razões: foi 0 ano do centenário da Abolição, que motivou uma série de ações de protesto que denunciavam as condições de vida dos negros no país, e 0 ano da Constituição, que incorporou pelo menos duas importantes reivindicações do movimento - a criminalização do racismo e o reconhecimento da propriedade das terras de remanescentes de quilombos. ${ }^{20}$

Os anos de 1995 e 2001 são os dois momentos seguintes. E $m$ 1995, foi realizada em Brasília uma marcha em comemoração aos trezentos anos da morte de Z umbi dos Palmares. E ra o primeiro ano do governo Fernando $\mathrm{H}$ enrique Cardoso, que criou então um G rupo de Trabalho Interministerial, o GTI, para a Valorização da População N egra, a partir do qual foram implementadas as primeiras iniciativas de ação afirmativa na administração pública federal. E 2001 foi 0 ano da III Conferência M undial de Combate ao Racismo, realizada em D urban, na Á frica do Sul, que mobilizou o governo e as entidades do movimento negro em sua preparação e resultou em novos acontecimentos, como a reserva de vagas para negros em algumas universidades, e novos compromissos assumidos pelo Estado brasileiro em âmbito internacional.

A história do movimento negro no Brasil não deve ser entendida como "descolada" da história contemporânea, tanto do Brasil como do mundo. $0 \mathrm{~s}$ marcos aqui registrados fazem sentido para o movimento negro e também para a história nacional, pois se relacionam com conjunturas como a A bertura política, o centenário da A bolição, a Constituinte e o governo Fernando H enrique Cardoso, entre outros. E les tiram sentido desses contextos e emprestam-Ihes novos sentidos e, neste processo, está a riqueza da história oral - 
por isso, podemos dizer que ela permite, não de modo exclusivo, a ampliação do conhecimento sobre o passado.

Retornemos aos documentos do SN I com os quais iniciamos estas reflexões. N eles não é difícil identificar uma temática central, que continua bastante atual no debate de hoje sobre a questão racial no Brasil: a idéia de que o movimento "caracteriza a existência de uma campanha para estimular antagonismos raciais no País", e que, "caso continue a crescer e se radicalizar", poderá vir a "originar conflitos raciais". Para completar, as manifestações observadas são classificadas como "manifestações de racismo negro" eo próprio A bdias do N ascimento é chamado de "conhecido racista negro".

$\mathrm{N}$ ão há dúvida de que o movimento negro tem favorecido de longa data, e não só a partir da década de 1970, a formação da idéia de uma identidade "negra" no país, em contraposição à idéia de um Brasil mestiço por excelência. As entrevistas com militantes do movimento negro permitem perceber como a construção dessa identidade "negra" está ligada a contextos histórico-culturais e a trajetórias individuais e se constitui como resposta à experiência de racismo. 0 u seja, essa identidade não está dada de antemão, ela é historicamente construída.

N esse ponto, gostaríamos de recorrer a M ichael Pollak, que, em seu clássico artigo publicado na revista E studos H istóricos, "M emória, esquecimento, silêncio", afirma que, para além de verificar que a memória coletiva é um dado positivo, cumpre verificar como ela se tornou fato positivo. E m suas palavras:

N ão se trata mais de lidar com os fatos sociais como coisas, mas de analisar como os fatos sociais se tornam coisas, como e por quem eles são solidificados e dotados de duração e estabilidade. A plicada à memória coletiva, essa abordagem irá se interessar portanto pelos processos e atores que intervêm no trabalho de constituição e de formalização das memórias (POLLAK, 1989, p. 4). 
O u seja, trata-se de analisar como, no Brasil, num determinado contexto, que estamos vivenciando particularmente agora, fortalece-se a identidade do "negro", em detrimento da idéia do "mulato". Poderíamos até dizer que "negro" e "mulato" se transformaram em espécies de "memórias em disputa" na reflexão sobre a sociedade brasileira de hoje.

Propomos tomar a história oral, nesse contexto, como um caminho possível para escaparmos à "essencialização" por trás dessas identidades cristalizadas e quase transformadas em "coisas". Ela pode trazer - mas não só ela, evidentemente - aquilo que $\mathrm{H}$ ebe M attos chama de "a compreensão e o respeito à dinâmica histórica das identidades socioculturais efetivamente constituídas" (MATTOS, 2003, p.129).

É bastante comum, nas narrativas de nossos entrevistados, que apareçam episódios considerados por eles como emblemáticos dentro de um processo de tomada de consciência da negritude. U m trecho da entrevista de Carlos A lberto M edeiros, militante do movimento no Rio de Janeiro desde a década de 1970, pode ajudar a entender esse processo. ${ }^{21}$ Sua mãe era natural do Rio $\mathrm{G}$ rande do Sul e costumava visitar a família, em Porto A legre, com o filho ainda pequeno, nos anos 1950-60. Essas viagens, segundo nos contou, foram importantes para a formação de sua consciência racial. N ão só isso: ele tem clareza de que o relato dessas experiências é importante para a entrevista e para o nosso projeto, o que nos leva ao último item relacionado na pauta para a mesa-redonda: os aspectos epistemológicos envolvidos na crítica da fonte oral. E aqui remetemos à dimensão antropológica da metodologia da história oral. 0 u seja, o que é dito é resultado da interação do entrevistado com 0 pesquisador e das opções muitas vezes conscientes daquele, que resolve o que dizer e para quem, com determinado propósito. Vejamos o que nos contou Carlos A lberto M edeiros:

M as uma coisa que marcou e é importante aqui para a nossa conversa mais diretamente [grifo nosso] eram as viagens para 0 
Rio $\mathrm{G}$ rande do Sul. (...) E u até estava pensando nessa ex periência, porque havia duas coisas sobre as quais nos advertiam sobre o Rio G rande do Sul: uma era o frio e a outra era o racismo. E eu tive experiências ambíguas com as duas. Por quê? 0 frio, eu descobri que também podia ser uma coisa legal. D escobri lá que gosto de frio. Claro, bem agasalhado, se não estivesse chovendo, você podia curtir bem o friozinho. E a coisa do racismo como era? E ra uma situação completamente diferente daqui, porque havia uma linha nítida de separação. N egros e brancos podiam conviver no trabalho, podiam até, de repente, torcer pelo mesmo time de futebol, mas o que as pessoas chamam de vida social - as festas e os clubes - era absolutamente segregado. 0 u seja, não aprendi sobre segregação lendo alguma coisa sobre os E stados U nidos. E u vivi a segregação. Vocêtinha os clubes de negros, como o Floresta Aurora, M arcílio D ias, Satélite Prontidão e, nas festas, tanto em casa quanto nos clubes, você não via brancos. E les não iam. N ão eram convidados, assim como os negros não iam aos clubes dos brancos, nem tampouco eram convidados. N ão era por classe, era por raça. Porque mesmo na favela havia festas para negros e festas para brancos. $E$ mesmo nos sindicatos. E ra absolutamente segregado.

Aí eu descobri outra coisa. G ostam de dizer que a diferença entre Brasil eE stados U nidos está no fato de que aqui a visão é multipolar, você tem várias categorias, e lá você tem negro e branco. N ão é nem bem assim lá, nem bem assim aqui. Porque aqui eu descobri que, no Rio G rande do Sul - e depois eu vi que isso não era só lá - , havia uma divisão bipolar. Foi lá que eu comecei a identificar pessoas com a pele mais clara, com a aparência menos negróide, como negras, porque elas não podiam ir nas festas dos brancos. Ao mesmo tempo, eu descobri que, tal como o frio, aquilo também tinha um lado muito interessante porque eu me sentia muito bem naquelas festas, naqueles ambientes. $D$ epois redaborando, você vai sempre redaborando... [grifo nosso] U ma coisa que estava clara, logo de cara, é que era um ambiente seguro no qual eu não seria discriminado. M as era mais do que isso: era o lugar onde eu me sentia valorizado, onde a menina mexia comigo, diferente dos lugares misturados. Porque aí você tem essa situação: é misturado, mas há uma 
hierarquia. Está todo mundo no mesmo espaço, mas há uma valorização diferente. ${ }^{22}$

A metodologia da história oral tem essa característica especialmente interessante: a de permitir o conhecimento de realidades sociais através da narrativa de histórias que condensam determinados significados sobre 0 passado. ${ }^{23}$ São momentos especiais de uma entrevista, breves narrativas inseridas na grande narrativa de história de vida, que encerram uma riqueza tal que se tornam especialmente "citáveis" para dar conta de determinadas experiências. N 0 caso das entrevistas do projeto "H istória do movimento negro no Brasil", é interessante observar que, muitas vezes, os entrevistados têm clara consciência de que os episódios emblemáticos que nos contam têm poder elucidativo, que permite a eles explicarem-se (a si e a sua militância no movimento negro) para nós.

A pesquisa " $\mathrm{H}$ istória do movimento negro no Brasil" permitiu 0 registro de muitas histórias com força narrativa especial. Maria Raimunda Araújo, ${ }^{24}$ a M undinha A raújo, figura de referência no movimento negro do Maranhão desde a década de 1970, contou-nos também uma. Professora em São Luís, M undinha ia ao Rio de Janeiro durante as férias. N uma dessas ocasiões, resolveu voltar para São Luís com o cabelo black e fez o que chamou de "seu movimento" para, em seguida, transformá-lo em um movimento de sensibilização dos outros, tanto negros como brancos.

E u só sei que teve a época... M as foi no final dos anos 1960, que já estava o movimento Black Rio, que, na Z ona N orte, eles estão todos com aqueles cabelos enormes, aí eles passavam perto de mim, cumprimentavam... Pronto, aí eu comecei a ver que eu estava relacionada de fato com uma comunidade. $\mathrm{E}$ achando aquilo muito bonito. Mas só eu disse: "Poxa, mas no Maranhão..." Porque eu ia pro Rio e passava assim uns três meses, porque professora tinha uns três meses. Q uando retornei, o cabelo já está bem carapinha. A h, aí foi um choque, acredita? Um choque. Eu acabei sendo a primeira mulher negra a usar o cabelo assim, natural. A i sim... 
Chamava a atenção da rua inteira.

Chamava a atenção e eu era agredida. Me davam vaia na rua: "Êh, mulher, de onde saiu isso?" "É Toni Tornado?" Eu preciso saber 0 ano em que Toni Tornado apareceu no festival com o cabelo black power, porque eles me chamavam de Toni Tornado: "Toni Tornado, vai alisar esse cabeIo!" 25 G ente, e eu era tímida. 0 magistério tinha me libertado para 0 fato de comunicar mais com desembaraço. $M$ as eu era tímida. E u disse: "N ossa, e agora?" M as nunca pensei, nenhum momento, em alisar o cabelo.

E studava na A liança F rancesa, era na $G$ onçalves $D$ ias, aqui em São Luís, e eu tinha que descer uma longa rua, que era a rua dos Remédios. Tinha um colégio particular, que era o colégio São Luís. Bastava ter um aluno na janela ou pela porta, e me via de longe. Aí eles vinham chegando para a porta, para as janelas. Q uando eu tinha que passar na porta do colégio, já estava aquela aglomeração só para me ver e dar vaia: "Êh, diabo, vai alisar esse cabelo!" "O que que é isso? É o cão? É não sei o quê?" E eu tinha que enfrentar isso, não sei quantos dias durante a semana, mas nunca mudei de rua. Eu poderia ir pela outra rua para não passar na porta do colégio. Eu dizia: "N ão. É o meu cabelo. E u não vou deixar que esses moleques me abatam."

Mas aquilo incomodava. Incomodava. E u era uma pessoa até então anônima, ninguém me olhava. D e repente toda a cidade te olha. Tu vais para o cinema - ainda sou da geração em que todas as pessoas iam ao cinema. E agora eu comecei mesmo a me impor: eu passava pelo meio, entre as fileiras e ia atélá na ponta. Porque quando eu via que eles iam começar a virar todos para olhar na hora em que eu assumia no salão, eu dizia: "Bem, deixa eu fazer logo o desfile para eles me olharem." Aí eu ia lá como se estivesse procurando lugar, até que achava um lugar e sentava. Se ia para essa rua do Comércio, entrava numa loja, quem estava vendendo parava de vender, quem estava comprando...

$\mathrm{N}$ aquela época. E desde aí tem gente que diz: "A $h$, tu passa pela gente e nem olha." E u digo: "D esde o tempo em que me vaiavam na rua que eu aprendi a ir olhando só para frente." $\mathrm{E} u$ andava olhando para frente. Camelô, que chamavam 
Possibilidades das fontes orais: um exemplo de pesquisa

nesse tempo de marreteiro, esses vendedores da rua, todo mundo se achava no direito de me vaiar: "É não sei o quê! É hippie?! É isso, é aquilo!"

$M$ as aí eu entro na universidade, as pessoas dão força, eu vou participar de um grupo de teatro, que é o Laborarte. Aí eu vou ter mais força é dessas pessoas: "Ai, que legal. E stá igual à Angela D avis." Q uer dizer, essas pessoas que tinham acesso à informação e tudo já viam a minha aparência vinculada com o movimento negro americano. É bem verdade, eu disse: "E u estava fazendo, por enquanto, o 'meu movimento'". Era isolado. Mas aí eu já começava a pensar: "N ão, eu tenho que fazer alguma coisa. Isso é mais sério do que pensam. ${ }^{26}$

M undinha A raújo fundou então, com outras pessoas, o Centro de Cultura N egra do Maranhão (CCN ), em 1979 - um centro de estudos e debates que tinha como objetivo sensibilizar as pessoas para a questão racial. U m dos freqüentadores do CCN foi Magno $\mathrm{Cruz}_{,}{ }^{27}$ que, nesse pequeno trecho com 0 qual encerramos este texto, relata como se deu sua transformação de mulato, ou "moreno", em "negro".

Aí, quando tinha alguns seminários ela me convidava. E isso eu participava, dos seminários. Q ual era a minha resistência em me engajar no trabalho do CCN ? E u não me considerava negro. Inclusive o meu apelido na faculdade era "M oreno". As pessoas sempre me chamavam, quem não conhecia meu nome, o pessoal de outras turmas me chamava de moreno. E eu era crente que eu era moreno. Então essa questão da identidade é muito complicada, não é? M as a M undinha também podia ser morena, não é? É . E ssas contradições... M as eu não dizia isso, que eu não ia porque não me considerava negro. Mas no fundo essa resistência eu tinha. A chava: como eu ia participar de uma entidade do movimento negro se eu não me considerava negro? $\mathrm{M}$ as com os seminários e com as palestras que houve muito, vieram vários historiadores, o Joel Rufino veio dar cursos... 
O CCN, na realidade, iniciou, a M undinha deu o encaminhamento que eu acho que foi o melhor possível, porque foi de formação. E ntão, as primeiras reuniões que eu fui no CCN eram reuniões de estudo. E ra uma sala talvez um pouquinho maior do que essa aqui, quando dava mais de trinta pessoas tinha que ficar gente do lado de fora, e era texto para gente ler, era jornal para gente ler, para discutir, livros... eu tinha que levar um livro para casa e na outra semana eu devolvia para alguém ler. E ntão foi formação mesmo para a gente aprender. $\mathrm{N}$ inguém sabia nada sobre a história do negro. E aí, com esses cursos, esses seminários que eu fui participando, mas muito assim, eu aí fui percebendo que era negro.

Era tanta coisa que o pessoal falava que eu me remetia à minha vida. Aí eu vou descobrir por que eu fui estudante profissional até 18, 19 anos e meu irmão trabalhou desde os 13. Aí eu fui descobrir por que quando eu ia nessa equipe que a gente montou para estudar do Liceu... tinha um colega nosso que era branco, a família dele era do interior, o pai dele tinha sido prefeito e quando terminou o mandato dele veio morar aqui, e tinha uma certa estrutura, uma estabilidade financeira, e a mãe dele era diretora de um colégio. E a gente só tinha aulas de manhã e de tarde. À noite a gente ia para esse colégio estudar, era o local onde a gente estudava. E ntão antes a gente tinha que passar na casa dele, todo mundo se encontrava lá, e de lá a gente ia para a escola. Pegava a chave e ia para a escola. E ra perto. E eu me lembro bem que no começo ele sempre dizia assim: "A qui é M agno e ele é o melhor aluno da turma." Aí, fazendo parte do movimento negro, eu vou descobrir que aquilo já era uma forma de discriminar, como quem diz assim: "A pesar de ser negro, ele..." Isso foi um choque para mim. Porque a militância também, ser militante não é aquele deslumbramento, você também descobre muita coisa ruim. E é assim. Claro que eu continuei sendo amigo dessas pessoas, mas sempre lembrando essas coisas que eles diziam de mim assim. Q uer dizer, me aceitavam não por eu ser eu, mas por eu ser o melhor aluno da turma. Então todo mundo fazia questão 
Possibilidades das fontes orais: um exemplo de pesquisa

de estudar comigo e, para me apresentar para uma família branca, eles tinham que justificar por que eu estava ali..28

N ossa reflexão se debruçou especialmente sobre o segundo item da relação de questões trazidas na pauta para a mesa-redonda: a história oral proporciona acesso a informações empíricas? Sim, por meio dessas "histórias dentro da história", que, a nosso ver, são mais do que simples ilustrações da realidade. Elas permitem que ampliemos nosso conhecimento sobre o passado. Como são fontes importantes para o estudo da história contemporânea do Brasil, precisam ser adequadamente guardadas e cuidadosamente disseminadas.

Thepossibilities of oral sources: a research example

Abstract: The aim of the paper is to present reflections on the possibilities of the oral history sources in historical researches. To accomplish this task, we have taken as example our own research, entitled "H istory of the black movement in B razil: organization of a collection of oral history interviews", developed between 2003 and 2007 at the Center for Brazilian Contemporary H istory Research and D ocumentation (CPD O C) at G etúlio Vargas Foundation, in Rio de Janeiro. A mong other subjects, we discuss the relations between oral history and politic history, the intersection between oral and written sources and the possibilities of knowledge enrichment provided by oral history.

Key words: O ral H istory - Black movement - Contemporary Brazil

N otas

${ }^{1}$ U ma primeira versão deste artigo foi apresentada por Verena A lberti na M esaredonda 2, "O historiador e as fontes orais", durante o IX E ncontro Estadual de $\mathrm{H}$ istória da A npuh do Rio G rande do Sul, em Porto A legre, no dia 15 de julho de 2008. Algumas das questões que nele discutimos foram apresentadas na mesa "A cervos e a produção interdisciplinar de estudos históricos I", durante o seminário "CPD O C 35 anos: a interdisciplinaridade nos estudos históricos", no Rio de Janeiro, em junho de 2008. As discussões em torno dos documentos do A rquivo E rnesto G eisel encontram-se esboçadas em A lberti e Pereira (2008).

${ }^{2} \mathrm{E} m$ seu primeiro ano de vigência, a pesquisa contou com o apoio do South-South Exchange Programme for R esearch on the H istory of D evelopment (Sephis) e, em

Anos 90, Porto Alegre, v. 15, n. 28, p. 73-98, dez. 2008 
janeiro de 2004, passou a integrar o projeto "D ireitos e cidadania", coordenado pelo CPD OC e aprovado pelo Programa de A poio aos N úcleos de Excelência (Pronex) do M inistério da Ciênciae Tecnologia. A s entrevistas do projeto constituem também o principal conjunto de fontes da tese de doutorado de A milcar A raujo Pereira, “O 'M undo negro': a constituição do movimento negro contemporâneo no Brasil (1970-2001)", que está sendo elaborada no Programa de Pós-G raduação em $\mathrm{H}$ istória da U niversidade Federal F luminense, sob orientação de $\mathrm{H}$ ebe M attos. Sobrea pesquisa, ver A Iberti e Pereira(2004, 2005, 2006, 2007a, 2007b, 2007c, 2007d, 2007e, 2007f, 2008).

${ }^{3} \mathrm{O}$ s documentos estão disponíveis para consulta no Portal do CPDOC (www.cpdoc.fgv.br).

${ }^{4}$ A bdias do N ascimento (1914) nasceu em Franca (SP), fundou o Teatro Experimental do N egro, em 1944, efoi um dos organizadores da Conven ção N acional do N egro, encontro realizado por dois anos (1945 e 1946), no Rio eem São Paulo, que propôs à Constituinte de 1946 a tipificação da discriminação racial como crime de lesa-pátria. Participou também como organizador do primeiro Congresso do N egro B rasileiro, em 1950. E m 1968 exilou-se nos E stados U nidos em decorrência do endurecimento do governo militar, no poder desde abril de 1964, e foi professor em diversas universidades norte-americanas. Participou dafundação do M ovimento N egro U nificado, em 1978, e criou, em 1981, o Instituto de Pesquisas e E studos Afro-Brasileiros (I peafro) na Pontifícia U niversidadeC atólica (PUC) de São Paulo. $\mathrm{N}$ o exílio, tornou-se amigo de Leonel Brizola, com quem fundou o Partido D emocrático Trabalhista (PDT) em maio de 1980. Fundou a Secretaria do M ovimento $N$ egro do PDT e foi deputado federal pelo Rio de Janeiro entre 1983 e 1986 e senador pelo mesmo estado de 1991 a 1992 e de 1997 a 1999. D urante o segundo governo de Leonel Brizola no estado do Rio de Janeiro (1991-1995), ocupou a Secretaria E xtraordinária para D efesa e Promoção das Populações A fro-Brasileiras (Sedepron), posteriormente denominada Seafro, e, durante o governo deA nthony G arotinho (1999-2003), foi secretário de D ireitos H umanos e da Cidadania do Rio de aneiro. Ver D icionário H istórico-B iográfico B rasilerro (D H BB ), edição revista eatualizada (Rio de Janeiro, E ditoraF G V, CPD O C, 2001).

${ }^{5}$ Florestan Fernandes (1920-1995) nasceu em São Paulo, filho único de uma imigrante portuguesa. Começou a trabalhar aos seis anos para ajudar a mãe, como ajudante de barbeiro, engraxate, num açougue em diversos locais. Como não pôde freqüentar a escola normalmente, aos 17 anos, matriculou-se num curso de madureza e, em 1940, concluiu os estudos. Cursou a F aculdade de Filosofia, Ciências e Letras daU SP de 1941 a 1943, formando-se em ciências sociais. Em 1947, obteve o título de mestre pela E scola Livre de Sociologia e Política de São Paulo, com uma dissertação sobre os Tupinambá, tema sobre o qual também versou sua tese de doutorado, defendidanaU SP em 1951. E m 1953, tornou-selivredocenteda cadeira de socio- 
Possibilidades das fontes orais: um exemplo de pesquisa

logia da USP. E nvolvido desde o início da década de 1950 com o Programa de Pesquisa sobre Relações Raciais no Brasil, patrocinado pela U nesco, Florestan Fernandes desmentiu a tese sobre a inexistência de racismo no Brasil. E m 1955, publicou com Roger Bastide N egros ebrancos em São Paulo, no qual inverteu a idéia de que o negro constituía um "problema" social, afirmando que a sociedade é que constituía um problema para a população negra. E m 1964, tornou-se catedrático em sociologia, com a tese $A$ integração do negro na sociedade de dasses, demonstrando como a desigual dade de acesso de negros e mulatos ao mercado detrabal ho constituía obstáculo para a realização de uma sociedade democrática no Brasil. Foi preso por ocasião do movimento político-militar de 1964, mas não ficou muito tempo na cadeia devido à grande repercussão de uma carta aberta que fez circular pela imprensa. N ão obstante, em 1969, foi afastado da USP e aposentado pelo A to Institucional no 5 (A I-5). E ntre 1969 e 1972, atuou como professor visitante nos EUA eno Canadá. A pós a redemocratização do país, elegeu-se deputado constituinte (1987-1988) e deputado federal (1988-1994) por São Paulo na legenda do Partido dos Trabalhadores (PT). Ver D H B B.

${ }^{6}$ Paulina L auraA Iberto encontrou no A rquivo Público do E stado do Rio deJ aneiro vários documentos da $D$ ireção $G$ eral de I nvestigações $E$ speciais (D G IE) quedemonstram que os organismos de repressão estavam atentos ao que era produzido pelas organizações do movimento negro durante aquele período. Ver Alberto, 2005.

${ }^{7}$ M ilton Barbosa, conhecido como Miltão, nasceu em Ribeirão Preto (SP) em 12 de maio de 1948. Q uando tinha três anos, mudou-se com a mãe e com a irmã para o bairro do Bexiga, na cidade de São Paulo, onde foi criado. Cursou economia na Universidadede São Paulo (USP), mas não concluiu, efoi diretor do Centro A cadêmico Visconde de Cairu da Faculdade de E conomia eA dministração daUSP, no ano de 1974. Como funcionário do M etrô, foi diretor daA Asociação dos Funcionários do M etropolitano de São Paulo (A emesp) entre 1978 e 1979, que mais tarde se transformou no Sindicato dos M etroviários. Foi um dos fundadores do M N U, tendo presidido 0 ato público de lançamento do movimento, no dia 7 de julho de 1978 , nas escadarias do Teatro M unicipal de São Paulo. E $m$ 1982, fez parte do D iretório Regional do Partido dos Trabalhadores do E stado de São Paulo, quando foi um dos fundadores da primeira Comissão de N egros do PT, na cidade de São Paulo. Foi presidente de honra na Convenção N acional do N egro em 1986, em Braślia. ${ }^{8}$ Trata-se do já mencionado I bea, fundado em 1975 pelo jornalista e historiador Clóvis M oura. Wilson Roberto Prudente foi militante em entidades do movimento negro de São Paulo e do Rio de Janeiro, onde atuou no projeto SO S Racismo do Instituto de Pesquisas das Culturas N egras (I PCN ), em 1987. M estre em sociologia e direito pela U niversidade Federal F luminense (UFF), com a dissertação I gualdade jurídica epensamento racial, defendida em 2002, atualmenteé procurador do M inistério Público do Trabalho, órgão do M inistério Público daU nião, etrabalhanaProcuradoria 
Verena Alberti e Almicar Araújo Pereira

Regional do Trabalho da 1ª̊ Região, no Rio de aneiro. Celso Luiz Prudente, seu irmão, éantropólogo, doutor em educação pela U niversidade de São Paulo (USP) e pesquisador do N úcleo de E studos e Pesquisas Interdisciplinares sobreo N egro Brasileiro (N einb) da mesma universidade. É autor, entre outros, de M ãos negras: antropologia da arte negra (São Paulo, E ditora Panorama, 2003). Ver www.jornaldaciencia.org.br/ D etalhe.jsp?id=17918, www.uff.br/ ppgsd/ disertacoes2002.html e www.unb.br/ acs/ unbagencia/ ag0206-28.htm, acesso em 1/ 8/ 2007.

${ }^{9}$ A dalberto Camargo (1923), político eempresário, foi diretor de várias empresas em São Paulo, entre elas a Táxi A marelinho S.A. E m 1968, fundou a Câmara de Comércio A fro-Brasileira, com a finalidade de estimular o comércio entreo Brasil e os países do continente africano. Foi o primeiro negro a se eleger deputado federa por São Paulo, em 1966, assumindo a cadeira em janeiro do ano seguinte. Reeleito três vezes, permaneceu ao todo quatro legislaturas na Câmara, de 1967 a 1983. Casou-se com E ster Lobo Camargo, com quem teve dois filhos. Provavelmente foi representado, na reunião citada por Milton Barbosa, por seu filho mais velho, A dalberto Camargo Júnior, que anos depois integrou a Coordenadoria E special do N egro da Prefeitura de São Paulo duranteo governo de Celso Pitta (1997-2000). Ver D H BB; I vo de Santana. "Relações econômicas Brasil-África: a Câmara de Comércio Afro-Brasileira e a intermediação de negócios no mercado africano." (E studos A froA siáticos, v. 25, n. 3, Rio de Janeiro, 2003), disponível em www.scielo.br ehttp:/ / www.al.sp.gov.br/ portal/ geral/ comissoes/ ata.jsp?idA ta $=266 \&$ comissao $=$ 8508\& legislatura=14, acesso em 1/ 8/ 2007.

10 "A fro-Latino-A mérica" era o nome da coluna de responsabilidade de $\mathrm{H}$ amilton Cardoso publicada no jornal V ersus, naépoca vinculado à Convergência Socialista. $\mathrm{H}$ amilton Cardoso também pertencia ao $\mathrm{N}$ úcleo $\mathrm{N}$ egro Socialista.

${ }^{11}$ E ntrevista realizada em São Paulo, em 19/ 7/ 2004.

${ }^{12} \mathrm{~A}$ discriminação de quatro negros pelo Clube de Regatas Ti ietêfoi comentadapelo $n^{\circ} 23$ do jornal V ersus, edição de julho/ agosto de 1978, p. 33: "O s quatro meninos atletas negros chegaram à porta do Clube de Regatas T ietê. H á muito esperavam para serem considerados militantes do clube, um dos melhores de São Paulo. Por que o negro não pode querer o melhor? Só porque nasceu na miséria? Muitos garotos praticam esportes no Clube Tietê. G arotos brancos. A o chegar, o porteiro explicou que não poderiam entrar. Um deles burlou o porteiro e chamou um dos técnicos, que os mandou entrar. 0 diretor do clube chamou o técnico para lhe explicar que os garotos não poderiam ser aprovados porque eram negros. O stécnicos, os atletas protestaram. (...) Um dos diretores do Clube explicou: 'Se deixo um negro entrar na piscina, cem brancos saem imediatamente'..."

${ }^{13}$ Com a desincompatibilização deE rasmo D ias do cargo de secretário de Segurança Pública do estado de São Paulo para concorrer a uma cadeira de deputado federal por São Paulo nas eleições de 1978, a Secretariafoi ocupada por Ê nio Viegas M onteiro 
Possibilidades das fontes orais: um exemplo de pesquisa

de L ima, entre março e novembro de 1978. Ver Síntese da ação governamental. G overno Paulo E gydio M artins - 1975/ 1979 (s.l., s.d.).

${ }^{14} \mathrm{Ver}$, a esse respeito, A lberti e Pereira (2007f, capítulo 2, e2007b).

${ }^{15} \mathrm{O}$ Brasil foi o primeiro país a reconhecer a independência de Angola, em 11 de novembro de 1975.

${ }^{16}$ Ver Alberti ePereira (2007f) capítulo 4.

${ }^{17}$ E ntre outros, Camargo (1994) eFerreira (1994).

${ }^{18}$ Salvatici (2005).

${ }^{19} \mathrm{H}$ erbert (1985). E ssa questão encontra-se também desenvolvida em A lberti (2004, capítulo 2).

${ }^{20}$ Respectivamente, item X LII do A rtigo 50 e A rtigo 68 dos A tos das D isposições Constitucionais Transitórias da Constituição de 1988.

${ }^{21}$ Carlos A lberto M edeiros (1947) engajou-se no movimento negro desde a década de 1970, quando participou dos primeiros encontros promovidos pelo recémcriado Centro deE studos A fro-A siáticos eda fundação da Sociedade del ntercâmbio Brasil-Á frica (Sinba) e do Instituto de Pesquisa das Culturas N egras (IPCN ), todos na cidade do Rio de Janeiro. Teve participação importante na articulação entre o movimento negro eas instâncias do poder público, na qualidade de chefe degabinete daSecretaria de E stado E xtraordinária de D efesa ePromoção das Populações N egras/ RJ (Seafro), no segundo governo Leonel Brizola, durante a gestão de A bdias do N ascimento, de quem foi assessor no Senado Federal (1997-1999). Foi também membro do G rupo de Trabalho Interministerial para a Valorização da População N egra, órgão do Ministério da Justiça (1995-1996). Subsecretário adjunto de Integração Racial naSecretaria deE stado dos D ireitos H umanos e da Cidadania/ RJ do governo A nthony $G$ arotinho, foi um dos primeiros defensores das políticas de ação afirmativa no Brasil.

${ }^{22}$ E ntrevista realizada no Rio de Janeiro, em 15/ 4/ 2004.

${ }^{23} \mathrm{Ver}$, a esse respeito, A lberti (2004).

${ }^{24} \mathrm{M}$ aria Raimunda (M undinha) A raújo nasceu em São L uís, em 8 de janeiro de 1943. Formada em comunicação social pela Federação das E scolas Superiores do M aranhão em 1975, M undinha A raújo, como é conhecida, foi fundadora do Centro de Cultura N egra do M aranhão (CCN ), em 1979, a primeira vice-presidente da entidade, de 1980 a 1982, e ocupou a presidência no mandato seguinte, de 1982 a 1984. Foi diretora do A rquivo Público do E stado do M aranhão entre 1991 e 2003. ${ }^{25}$ A ntônio V ianaG omes (1930), o Tony Tornado, interpretou a composição "BR-3", deTibério G aspar e Antônio A dolfo, acompanhado pelo Trio Ternura, no V Festival Internacional da Canção, em 1970. Ver http:/ / www.dicionariompb.com.br/ detalhe.asp?nome $=$ Tony + Tornado $\&$ tabela $=$ T_FO RM_A \& qdetalhe $=$ art, acesso em 23/ 7/ 2007.

${ }^{26}$ E ntrevista realizada em São L uís, em 10/ 9/ 2004. 
${ }^{27}$ M agno Cruz nasceu em São Luís em 25 de maio de 1951. E ngenheiro formado pela U niversidade E stadual do M aranhão em 1976, éfuncionário da Companhiade Á gua e E sgotos do M aranhão (Caema) desde 1980. Foi presidente do Centro de Cultura N egra do Maranhão (CCN) por dois mandatos consecutivos, de 1984 a 1988. À época da entrevista, era presidente do Conselho D iretor da Sociedade $M$ aranhense de Direitos H umanos e era diretor de formação do Sindicato dos Urbanitários do M aranhão, filiado à Central Ú nica dos Trabalhadores (CUT).

${ }^{28}$ E ntrevista realizada em São Luís, em 8/ 9/ 2004.

\section{Referências}

ALBE RTI, Verena. 0 uvir contar. Rio de Janeiro: E ditora FG V, 2004.

ALBE RTI, Verena ePereira, A milcar A raujo. "H istória do movimento negro no Brasil: constituição de acervo de entrevistas de história oral". Trabalho apresentado no III Congresso B rasileiro de Pesquisadores N egros "Pesquisa Social e Políticas de A ções A firmativas", realizado em São Luís, naU niversidadeFederal do M aranhão, de 6 a 10 de setembro de 2004. D isponível em www.cpdoc.fgv.br, acesso em 17/ 01/ 2009.

. “M ovimento negro e 'democracia racial' no Brasil: entrevistas com lideranças do movimento negro". Trabalho apresentado durantea III Conferência Bienal daA ssociação parao E studo da D iásporaA fricana M undial (TheA ssociation for the Study of the Worldwide A frican Diaspora - A SWAD ), realizada no Rio de Janeiro em 5, 6 e 7 de 0 utubro de 2005. D isponível em www.cpdoc.fgv.br, acesso em 17/ 01/ 2009.

A defesa das cotas como estratégia política do movimento negro contemporâneo. E studos H istóricos, Rio de Janeiro, n. 37, p. 143-167, jan./ jun. 2006. D isponível em www.cpdoc.fgvibr, acesso em 17/ 01/ 2009.

- 2007a - D iscriminación racial en Brasil: líderes del movimiento negro. H istoria, A ntropología y F uentes 0 rales, Barcelona: Publicacions U niversitat de Barcelona, n. 37, p. 23-31, año 2007 (3á́ poca).

- 2007b - Q ual Á frica? Significados daÁ frica para o movimento negro no Brasil. E studos H istóricos, Rio deJ aneiro: Centro de Pesquisa e D ocumentação de H istória Contemporânea do Brasil da Fundação G etulio Vargas, n. 39, p. 25-56, janeiro-junho 2007. D isponível em www.cpdoc.fgv.br, acesso em 17/ 01/ 2009.

- 2007c - 0 movimento negro contemporâneo. In: FERREIRA, Jorge e REIS, D aniel A arão (O rgs.). R evolução edemocracia: 1964... Rio de Janeiro: Civilização B rasileira, 2007, p. 637-669 (As esquerdas no Brasil; v.3). 
Possibilidades das fontes orais: um exemplo de pesquisa

- 2007d - Articulações entre movimento negro e Estado. I n: G O MES, Angela de Castro (Coord.). D ireitos ecidadania: memória, política e cultura. Rio de Janeiro: E ditora FG V, 2007, p. 93-113.

- 2007e- "Transformação de entrevistas em livro: uma experiência de ediçẫo" , trabalho apresentado no VII E ncontro Regional Sudestede História O ral, realizado no Rio de Janeiro, novembro 2007.

- 2007f - H istórias do movimento negro no Brasil: depoimentos ao CPDOC. Rio de Janeiro: Pallas, CPD O C-FG V.

. Pesquisando o movimento negro no Brasil. Revista de $H$ istória da Biblioteca N acional, Rio de Janeiro, v.3, n.36, p.40-44, set.2008.

ALBE RTO, Paulina Laura. Black A ctivism and the C ultural C onditions for C itizenship in a M ulti-R adal Brazil, 1920-1982 (D issertation in H istory Presented to the Faculties of the University of Pennsylvania in Partial Fulfillment of the Requirements for the D egree of D octor of Philosophy, 2005).

CAM ARG O, A spásia. História oral e política. In: FE RRE IRA, Marieta de Moraes (O rg.), H istória oral emultidisciplinaridade. Rio de Janeiro, D iadorim/ Finep, 1994, p. 75-99.

FE RRE IRA, M arieta de M oraes. H istória oral: um inventário das diferenças. In: FE RRE IRA, M arieta deM oraes (O rg.) E ntrevistas: abordagens eusos dahistória oral. Rio de Janeiro: E ditora da F undação G etúlio Vargas, 1994, p. 1-13.

HERBERT, U Irich. Zur Entwicklung der Ruhrarbeiterschaft 1930 bis 1960 aus erfahrungsgeschichtlicher Perspektive In: NIET H AM ME R, Lutz ePLATO, A lexander von (O rgs.). "W ir k riegen jetzt andere Z eiten". A uf der Suche nach der E rfahrung des $V$ olkes in N achfaschistischen L ändern. L ebensgeschichte und Sozialkultur im Ruhrgebiet 1930 bis 1960 (Lusir), Bd. 3., Berlin-Bonn, J.H .W. D ietz N achf., 1985, p. 19-52.

MATTOS, H ebeM aria. $O$ ensino dehistóriaea luta contra adiscriminação racial no Brasil. In: ABREU, M. eSO IHE T, R. (O rgs.). E nsino de história: conceitos, temáticase metodologia. Rio de Janeiro: Casa da Palavra, 2003, p. 127-136.

PO LLAK, Michael. Memória, esquecimento, silêncio. E studos H istóricos, Rio de Janeiro: CPD 0 C-FG V, v. 2, n. 3, p. 3-15, 1989. D isponível em www.cpdoc.fgv.br, acesso em 17/ 01/ 2009.

SA LVATICI, Silvia. M emórias de gênero: reflexões sobrea história oral demulheres. H istória 0 ral - Revista da A ssociação B rasileira deH istória O ral, São Paulo, ABH O, v. 8, n.1, p. 29-42, jan.-jun. 2005.

Recebido em 05/ 09/2008

A provado em 30/09/2008 